\title{
Title: Understanding the pharmacokinetics of mamajjaka (enicostemma littorale blume) as a dietary supplement in diabetes mellitus.
}

\begin{tabular}{ll}
\hline & \\
& \\
1. & Puthor: \\
2. & P.G. Schorolar, \\
3. & Assistant Professor,
\end{tabular}

Dravyaguna Dept., Government Ayurveda College, Osmanabad 413501, India.

*Corresponding Author: email -dvkulkarni13@gmail.com (9284679341)

\section{ABSTRACT:}

Enicostemma littorale Blume, also known as Mamajjaka in Sanskrit, Indian gentian in English and "Kadavinay" in local language, is a perennial herb Gentianaceae family. The plant parts 1 leaves and roots are used since ages various parts of India for treating diabetes. It is widely used in Solapur and Osmanabad districts of Maharashtra, in the form of "leaf pickle" as a dietary supplement in diabetic patient. Acharya Priyavat Sharma has described it as useful in madhumeha. Mamajjaka has a predominance of Tikta rasa, Ushna virya, Katu vipaka, Laghu-Ruksha guna and Vayu-Aakash mahabhuta. It's an easily available and economically important herb. Different constituents of Mamajjaka, like Swertiamarin, Flavonoids, Saponins, triterpenoids, alkaloids, catechins, sterols, phenolic acids and xanthones, have been reported for possessing hypoglycemic properties. In-vivo, anti-hyperglycemic effect of Mamajjaka has been established, through enhancing glucose-induced insulin release, reducing the glycosylated hemoglobin and by inhibiting the action of glucose-6-phosphate in liver. As, all previous studies have established the significant potentials of Mamajjaka both in Type- 1 and Type- 2 diabetes, in this study we have reviewed the pharmacoinetics of Mamajjaka, keeping in mind the scientific basis of traditional use of Mamajjaka mainly as diet in diabetes. We have established the role of panchabhautic constitution of Mamajjaka as a dietary supplement for the diabetic patients. We have concluded that Mamajjaka, being cost-effective and easily available medicinal herb possessing hypoglycemic properties, can be used as an excellent vegetable in diabetic patients as a dietary supplement.

\section{Keywords:}

\section{Enicostemma littorale, Mamajjaka,} Ayurveda, Anti-diabetic.

\section{Introduction:}

Diabetes is a serious, chronic, complex disorder associated with metabolic disturbances and hyperglycemia. 
Management of diabetes without any side effect is still a challenge to all clinical practitioners. Current scenario of diabetes says that there were 72 million cases of diabetes in India in 2017. Also, according to International diabetic federation, 425 million people have diabetes in all over world and 82 million in South-East Asia region $^{[1]}$.

There are plenty of drugs available as an oral hypoglycemic agent to lower blood glucose level in diabetics. However, most of them are expensive and unpalatable and also with many side effects. Therefore, finding of more preventive strategies and treatments especially as dietary supplement is vital. One of such herbal plants is Enicostemma littorale Blume. i.e. Mamajjaka, which can be used as a dietary supplement.

In his Priya-Nighantu, Acharya Priyavat Sharma has described Mamajjaka as useful herb in Madhumeha ${ }^{[2]}$. This plant found to be distributed in grasslands, forests to beaches, from wet to very dry and also survives in a very saline environment, throughout India. Medicinal compounds derived from Mamajjaka, are considered to be very effective, since these are eco-friendly, palatable, possessing long shelf life and free from side effects ${ }^{[3]}$.

\section{Madhumeha -}

It is mentioned in Bruhattrayis. In the samprapti of Madhumeha, Acharya Sushruta has described that prameha is not treated at a right time i.e. Kalen apratikarinah, then it is converted into Madhumeha and said to be Asadhya i.e. incurable. $^{[4]}$

According to Acharya Charaka, in the samprapti of Madhumeha, increased Kledadi dushya's get forcefully pulled by dushit vata dosha into the Basti causing increase in the quantity along with the turbidity of urine, which can be labeled as Prabhuta aavila mutrata. ${ }^{[5]}$

\section{Diabetes -}

Normally ingested food is converted into glucose by the liver and glucose is released in the blood stream. At the same time pancreatic beta cells get triggered for the insulin release. This released insulin, then stimulates the insulin receptors placed on the surface of cells, to facilitate the entry of the glucose into the cells. Thus blood glucose level gets maintained and body cells get energy from glucose.

Type 1 diabetes: In this, pancreatic beta cells are unable to produce sufficient insulin. Due to which insulin receptor does not get stimulation for glucose uptake by cells and thus glucose remains in the blood stream.

Type 2 diabetes: In this, pancreatic beta cells produce insulin properly, but there is a condition of alterations in insulin receptor which lead to insulin resistance. Due to insulin resistance blood glucose cannot move into the cells and thus glucose remains in the blood stream. Here there may be the condition of hyperinsulinemia also.

In this way, in both type of diabetes blood glucose level get increased. ${ }^{[6]}$

\section{Nutritive value of Mamajjaka -}

Table- 1: Nutritive value per $100 \mathrm{gm}$ of fresh leaves of Mamajjaka (E. littorale) (According to report of Indian Council of Medical Research) ${ }^{[7]}$

\section{\begin{tabular}{|l|l|} 
Components & Amount
\end{tabular}}




\begin{tabular}{|l|l|}
\hline Energy (Kcal) & 140 \\
\hline Protein $(\mathrm{gm})$ & 7 \\
\hline Fat $(\mathrm{gm})$ & 0.7 \\
\hline Carbohydrate $(\mathrm{gm})$ & 26.5 \\
\hline Fiber $(\mathrm{gm})$ & 4.2 \\
\hline Minerals $(\mathrm{gm})$ & 8.4 \\
\hline Iron $(\mathrm{mg})$ & 49.9 \\
\hline Calcium $(\mathrm{gm})$ & 1.641 \\
\hline Phosphorous $(\mathrm{gm})$ & 81 \\
\hline
\end{tabular}

\section{Phytoconstituents -}

- 5 alkaloids, 2 sterols and volatile oil ${ }^{[8]}$

- A triterpene sapogenin - betulin ${ }^{[9]}$

- Monoterpene alkaloids - enicoflavin, gentiocrucine and 7 different flavonoids.isolated from alcoholic extract. And structures were identified as apigenin, genkwanin, isovitexin, swertisin, saponarin, glucosylswertisin. ${ }^{[10]}$

- Saponins, catechins, sapogenin, triterpenoids, flavonoiets: and xanthones, a new flavones cglucoside named as Verticilliside ${ }^{[11]}$

- Swertiamarin ${ }^{[12]}$

- 6 phenolic acids - vanillic acid, syringic acid, p-hydroxy benzoic acid, protocatechuic acid, p-coumaric acid and ferulic acid ${ }^{[13]}$

- Different amino acids - L-glutamic acid, tryptophane, alanine, serine, aspartic acid, L-proline, L-tyrosine, threonine, phenyl alanine, L-histidine monohydrochloride, methionine, iso leucine, L-arginine monohydrochloride, DOPA, Lglycine, 2-amino butyric acid and valine. ${ }^{[14]}$

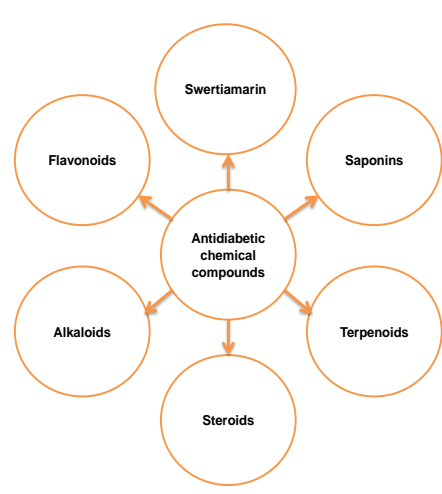

Fig. 1 Anti-diabetic chemical compounds present in Enicostemma littorale Blume. $\underline{\text { (Mamajjaka) }}$

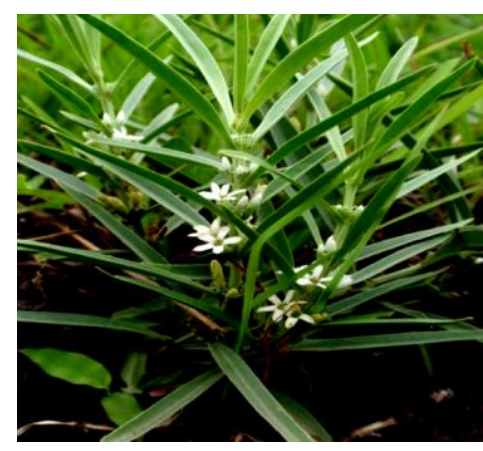

Fig. 2 Mamajjaka (Enicostemma littorale Blume. $)^{[15]}$

\section{Previous workdone:}

1. Jyoti M [2000], Murali B. [2002] and others found that a single dose of aqueous extract of Mamajjaka (15g dry plant equivalent extract $/ \mathrm{kg}$ ) had shown significant increase in serum insulin levels in alloxan induced diabetic rats at $8 \mathrm{hr}$. further insulinotropic action of this extract also investigated using rat pancreatic islets and it reveals that plant extract has potential to enhance glucose induced release at $11.1 \mathrm{mM}$ glucose from and was partially able to reverse the effect of diazoxide. Incubation with $\mathrm{Ca} 2+$ chelator and $\mathrm{Ca} 2+$ channel blocker (nimodipine) did not affect the 
glucose-induced insulin release augmented by the extract. Thus above results have suggested the glucose lowering effect of aqueous extract of Mamajjaka. ${ }^{[19,3]}$

2. In diabetes, hyperglycemia generates more reactive oxygen species (ROS). This increased ROS production and compromised anti-oxidant defense system leads to a decrease in glutathione (GSH) levels, increase LPO and change in CAT activity. GSH is an important factor in detoxification and antioxidant systems. GSH offers protection against oxygen derived free radicals and cellular lethality. An increase in GSH level in extract treated diabetic rats might be due to less production of ROS.

3. Jyoti Maroo and others [2003] found that methanol extract of Mamjjaka decreases the glycation of $\mathrm{Hb}$ and live glucose-6-phosphatase activity alloxan induced diabetic rats. She also found increase in GSH levels; decrease in erythrocyte CAT activity and decrease in erythrocyte LPO levels in extract treated diabetic rats. ${ }^{[20]}$

4. Jyoti M. and others [2003] found that administration of aqueous extract of Mamajjaka for 45 days showed reduction in blood glucose levels. ${ }^{\text {[21] }}$

5. Maroo J. and others [2002] found that Mamjjaka potentiate the glucose induced insulin release from pancreatic beta cells and cause a decrease in blood glucose levels of extract treated diabetic rats. ${ }^{[22]}$

6. Maroo J. and others [2003] established that Mamajjaka is a potent antidiabetic agent without any toxic effect at this particular dose (1.5g dry plant equivalent extract/100gm body wt.) in alloxan induced diabetic rats. They also found the significant decrease in glycosylated haemoglobin, liver glucose-6-phosphatase activity and significant increase in serum insulin level of diabetic rats. ${ }^{[23]}$

7. Vishwakarma Santosh L. and others [2003] found the dose dependent effect of hot and cold aqueous extract of Mamajjaka $(0.5,1$ and $2 \mathrm{gm} / \mathrm{kg}$ for 3 weeks) on streptozotocin induced type 1 diabetic rats. It also posses potential of antidiabetic activity and improves lipid profile at a small dose of $0.5 \mathrm{~g} / \mathrm{kg}$. $\mathrm{He}$ also found that treatment of diabetic rats with hot aqueous extract reduced the food, water intake and glucose and AUC glucose levels and decreased the serum glucose, serum cholesterol and triglyceride levels. Swertiamarin was found to be a major component in hot extract of Mamajjaka while it was absent in cold extract $^{\text {[24] }}$

Upadhyaya and others [2004] found that, Mamajjaka is administered in ayurvedic pill form for treating type 2 diabetes since it plays a major role in reducing blood glucose and increases serum insulin level and significantly improves kidney function, lipid profile, systolic and diastolic blood pressure and pulse rate. ${ }^{[25]}$

9. Prince PSM and others [2005] found that administration of aqueous extract of Mamajjaka for 45 days significantly decreases the blood glucose, TBARS (Thiobarbutyric acid), SOD (Superoxide dismutase), CAT (Catalase) and $\mathrm{GP}_{\mathrm{x}}$ (Glucose peroxidase) in alloxan induced diabetic rats. When the effectiveness of Mamajjaka extract was compared with standard drug insulin, then it was observed that administration of 
Mamajjaka extract at the dose of $2 \mathrm{gm} / \mathrm{kg}$ was more effective than insulin at the dose of 6 units $/ \mathrm{kg}$. Hence it can be tried in clinical purpose to overcome these complications. ${ }^{[26]}$

10. Jaishree Vaijanathappa and others [2008] found that aqueous extract of Enicostemma axillare prevented the blood glucose level as well as insulin level in rat model. It produces an increase in insulin sensitivity, normalizes dyslipidaemia and provides nephroprotection in diabetic rats. ${ }^{[27]}$

11. Gite and others [2010] concluded that the leaf of Mamajjaka possesses hypoglycemic, anti-oxidant, hepatoprotective and hepatomodulatory properties and helps in reducing obesity ${ }^{[28]}$.

12. The multi-potent differentiation property of stem cells opens up new arena for the treatment of the diabet. patients. Many chemical biochemical compounds make stem cells get differentiate into insulin producing cells.

13. Sarita Gupta and others [2010] in their study highlighted the islet neogenic property of the plant Mamajjaka. An active herbal compound SGL-1 (Sodium glucose transporter) was isolated and purified from extract of Mamajjaka and used to differentiate two model stem cell lines PANC-1 and NIH3T3 which showed tremendous islet neogenic potential and significant islet yield compared to control serum free medium. Morphological, molecular and immunological characterization of newly generated islet like cellular aggregates proved them differentiated and positive for islet hormones. Functional characterization of islet cellular aggregates (ICA's) confirmed significant glucose responsive insulin release. This preliminary data offer exiting possibility of alternate source to increase islet mass which can be used for diabetic treatment. ${ }^{[29]}$

14. Shukla Amarnath and others [2013] concluded that Mamajjaka extract for 45 days significantly reduced hyperglycemia in type 2 diabetes mellitus. ${ }^{[30]}$

15. Insulin resistance is responsible for the development of hyperglycemia in NIDDM (non insulin dependent diabetes mellitus) patients. Gohil T. A. and others [2008] found that administration of aqueous extract of Mamajjaka for 15 days prevented hyperglycemia and hyperinsulinemia induced by a diet high in fructose. ${ }^{[31]}$

6. Gopal R. and others [2004] found that, the aerial part of the Mamajjaka reduces the serum cholesterol level in hepatoma bearing rats. This activity is through a component of plant which enhances cholesterol acyl transfereras by esterification of free cholesterol in the HDL (High density lipoprotein). ${ }^{[32]}$

17. Vihas T. Vasu and others [2005] found the hypolipidaemic and antioxidant effect of aqueous extract of Mamajjaka at a dose of $1.5 \mathrm{~g} / 100 \mathrm{~g}$ body wt/day, to rats along with hypercholesterolaemic diet. It also showed a decrease in activities of erythrocyte catalase, superoxide dismutase and lipid peroxidation levels, with an increase in reduced glutathione levels compared to untreated rats. Also there were decrease in kidney and liver cholesterol level. ${ }^{[33]}$ 
18. Hitesh Vaidya and others [2009] demonstrated new property of Swertiamarin as a potent lipid lowering agent and comparable to atorvastatin and it may contribute to its cardioprotective and antiatherosclerotic role. Swertiamarin and atorvastin when orally fed also lowered the total serum cholesterol and triglycerides. ${ }^{[34]}$

19. Jaishree Vaijanathappa and others [2008] also found the anti-oxidant and hepatoprotective properties of Swertiamarin isolated from Enicostemma axillare. ${ }^{[27]}$

20. Gupta R. S. and others [2007] found the administration of ethanolic extract of Mamajjaka exhibited the significant hepatomodulation against oxidative stress in rats through anti-oxidant potential and free radical scavenging activities along with reduction of $f$ metabolism. ${ }^{[35]}$

21. Flavonoids are polyphenolic compounds which show an antioxidant effect by quenching free radicals. This might be the reason for the decrease in the erythrocyte CAT activity and LPO in extract treated diabetic rats.

22. Natarajan [1972], Ghosal [1980] and others found that extract treatment of diabetic rats decreases blood glucose levels, thereby decreasing glucose auto-oxidation and free radical generation, which in turn decreases lipid peroxidation activity. Phytochemical analysis of Mamajjaka has shown the presence of different flavonoids and alkaloids. ${ }^{[36,37]}$

23. Bhatt NM and others [2009] found the protective effects of Mamajjaka for hypoglycemic and antioxidant activity in alloxan induced diabetic neuropathy in male Charles foster rats. They also found changes in lipid peroxidation (LPO) and anti-oxidant enzymes like SOD, $\mathrm{GP}_{\mathrm{x}}$ and CAT levels, decrease in Na-K ${ }^{+}$ATPase activity were also restored by Mamajjaka treatment. This study provides an experimental evidence for the preventive effect of Mamajjaka on nerve function and oxidative stress in animal model of diabetic neuropathy. Hence Mamajjaka may be clinically tried for treating diabetic neuropathy since it was used as a folklore medicine in diabetic patients. ${ }^{[38]}$

\section{AIM:}

Understanding the pharmacokinetics of Mamajjaka (Enicostemma littorale Blume) as a dietary supplement in Diabetes Mellitus.

\section{BJECTIVES:}

Primary objective -

To study madhumehahar activity of Mamajjaka as a dietary suppliment with special reference to antidiabetic mechanism.

\section{Secondary objective -}

To study rasapanchak, panchbhoutik constitution and phytochemical composition of

Mamajjaka.

\section{OBSERVATIONS:}

Mamajjaka widely used in Solapur and Osmanabad districts of Maharashtra, in the form of "leaf pickle" as a dietary supplement in diabetic patient. According to Acharya Priyavat Sharma in Priyavat Nighantu, Mamajjaka has predominance of Tikta rasa, Katu vipaka, Ushna virya, Vayu-Aakash mahabhuta and laghu ruksha guna. ${ }^{[16]}$ From previous work 
done, it is observed that, Mamajjaka contains some anti-diabetic chemical compounds due to which it acts as hypoglycemic agent as well as useful in diabetic complications. These anti-diabetic compounds include, Flavonoids, Saponins, Alkaloids, Steroids, Terpenoids and specially Swertiamarin. It acts in diabetes and related comlicatinos by reducing the TBARS (Thiobutyric acid), LPO (Lipid Peroxidase), ROS (Reactive Oxygen Species) damage, LDL (Low Density Lipoprotein) and TG (Triglycerides) levels as well as by increasing CAT (Catalase), $\mathrm{GP}_{\mathrm{x}}$ (Glutathione Peroxidase), SOD (Superoxide Dismutase), GSH (Glutathione) anti-oxidant and HDL (High Density Lipoprotein) levels in the serum. by "Shamam ch Kaphavatayoh" property, Ushna veerya reduces the Kledadi dushya by Laghu Ruksha guna and Vayvakash mahabhuta reduces kledadi dushya by cleansing (vishada), porus (soushirya), lightens (laghavkar) property. ${ }^{[18]}$

From the above study anti-diabetic activity of Mamajjaka can be grouped as follows:

1. It reduces Glucose-6-phosphatase activity there by reducing the blood sugar level.

2. It increases the insulin sensitivity by stimulating insulin receptor and increases glucose absorption.

3. It stimulates to pancreatic beta cells for more insulin secretion.

4. It has islet neogenic property of beta cells so increasing insulin secretion.

\section{RESULTS:}

From previous study, finding is that, Its mechanism in preventing diabetic raspanchaka of Mamajjaka helps Sampraptibhanga of Prameha especial: Madhumeha. Also chemical constituents of Mamajjaka has significant anti-diabetic potential both in type-1 and type-2 diabetes. As well as it helps to prevent both acute and chronic diabetic complications due to its anti-oxidant, antihyperlipidaemic and anti-hyperglycemic property.

\section{DISCUSSION:}

According to Ayurveda, rasapanchaka of Mamajjaka helps in sampraptibhanga of Madhumeha. According to Acharya Charaka Tikta rasa reduces the kledadi dushya by "moistness (kleda), fat with cholesterol (medo), adipose tissue (vasa), (majja), lymh (lasika), pus (puya), sweat (sweda), urine (mutra), stool (purisha), bile (pitta), cough (shleshma) absorption (upshoshanah)" property $^{[17]}$, Katu vipaka helps to reduce increased kaphavata dosha

\section{CONCLUSION:}

From the above study, we can conclude that Mamajjaka is in possession of significant anti-diabetic potentials as well as it works as hepato-protective, nephroprotective, cardioprotective and anti-oxidant. Due to the cost-effective, easily available, harmless and palatable properties, we can use Mamajjaka as a dietary supplement in the form of "leaves pickle" for diabetic patients in day to day practice. Mamajjaka is not only having anti-diabetic potentials, but it also has efficacy against diabetic 
complications. These attributes provide the validation for the use of Mamajjaka in diabetes by traditional healers in India.

\section{ACKNOWLEDGEMENT:}

I have grateful to all teacher staff and all PG colleagues of Dravyaguna department, Government Ayurved College, Osmanabad.

\section{References -}

1. http://www.idf.com, www.diabetesatlas.org. IDF DIABETES ATLAS, $8^{\text {th }}$ edition, Brussels, Belgium, cited on 14 Feb. 2018

2. Aacharya Priyavat Sharma Dravyaguna Vidnyana, part-2, edition - reprinted 2005, published by - Chaukhamba Sanskrit Sansthan Varanasi, page no.- 704.

3. Murali B, Upadhyaya UM, Goy RK. Effect of chronic treatme with Enicostemma littorale in noninsulin dependent diabetic rats. J Ethnopharmacol 2002; 81: 199-204.

4. Ambikadatta Shastri - Sushruta Samhita, Nidanasthana 6, Pramehanidana Adhyaya, edition reprinted 2001, published by Chaukhamba Sanskrit Sansthan Varanasi, page no.- 255.

5. Yadavji Trikamji, Charaka Samhita - Agnivesha revised by- Charaka and Dridhabala with Dipika commentary of Chakrapanidatta. Nidansthan 06, Pramehnidan Adhyaya, Reprinted 2005, Published by - Chaukhamba Sanskrit Sansthan Varanasi;

6. www.ijdr.in. Diabetes: Mechanism, pathophysiology and management A Review.
7. Sathishkumar R, Lakshmi PTV, Annamalai A. Effect of drying treatment on the content of antioxidants in Enicostemma littorale Blume. Res J Med Plant 2009; 3(3): 93-101

8. Garad MC, Upadhya MA, Kokare DM, Itankar PR. Aerial parts of Enicostemma littorale Blume serve as anti-pyretic and antacid: in vivo and in vitro evaluations. Pharmacogn commun 2012; 2(3): 42-45.

9. Dymoc W, Warden CJH, Hooper D. Pharmacographica indica , Calcutta:Thacker, Spink \& Co.; 1893, vol 2, p. 516

10. Ghosal SS, Sharma AK, Chaudhuri PV. Chemical constituents of Gentianaceae 9; natural occurrence of erythrocentaurin in Enicostemma hissopifolium and Swertia lawii. J Pharm Sci 1974; 63: 944-945

11. Jhan E, Perveen S, Malik A. Verticilliside, a new flavones Cglucoside from Enicostemma verticilliside. J Asi Nat Prod Res 2009; 11: 257-260

12. Leelaprakash G, Mohan Dass S. Antimicrobial activity and phytochemical screening of methanol extract of Enicostemma axillare. Int J Pharm Sci 2012; 4(1): 342-348

13. Desai PD, Ganguly AK, Govindachari TR, Joshi BS, Kamat VN, Manmade AH, et al. Chemical investigation of some Indian medicinal plants: part 2 Ind J Chem 1966: 4: 457-459

14. Sathiskumar R, Lakshmi PTV, Annamalai A. Comparative Analyses of non enzymatic and enzymatic antioxidants of 
Enicostemma littorale Blume. Int J Pharma Bio Sci 2010; 1(2): 1-16

15. https://sites.google.com and Enicostema axillare - eflorafindia.

16. https://08511630493324166816.goo glegroups.com, cited on 14 Feb. 2018

17. Aacharya Priyavat Sharma Dravyaguna Vidnyana, part-2, edition - reprinted 2005, published by - Chaukhamba Sanskrit Sansthan Varanasi, page no.- 704.

18. Yadavji Trikamji, Charaka Samhita - Agnivesha revised by Charaka and Dridhabala with Dipika commentary of Chakrapanidatta. Sutrasthana, 26, Aatreyabhadrakapyiya Adhyaya, Reprinted 2005, Published Chaukhamba Sanskrit Sansthan Varanasi; page no. 368

19. Ambikadatta Shastri - Sushruta Samhita, Sutrasthana Dravyavisheshvidnyaniya Adhyay edition - reprinted 2001, published by - Chaukhamba Sanskrit Sansthan Varanasi, page no.- 154.

20. Jyoti, M., Vasu, V. T. Ravikumar, A and Sarita, G. Glucose lowering effect of aqueous extract of Enicostemma littorale Blume in diabetes a possible mechanism of action. Journal of Ehnopharmacol, 2000; 81: 199-204.

21. Jyoti Maroo, Arna Ghosh, Rajni Mathur, Vihas T. Vasu and Sarita Gupta. Antidiabetic efficacy of Enicostemma littorale Methanol extract in Alloxan-induced diabetic rats. Pharmaceutical Biology. 2003, Vol. 41, No. 5, pp. 388-391.

22. Jyoti, M., Vasu, V.T. and guptam, S. Dose dependent hypoglycemic effect of aqueous extract of
Enicostemma littorale blum in alloxan induced diabetic rats. Phytomedicine, 2003; 10: 196-199.

23. Maroo J, Vasu VT, Aalinkeel R, Gupta S (2002): glucose lowering effect of aqueous extract of Enicostemma littorale Blume in diabetes: A possible mechanism of action. J Ethnopharmacol 81: 317320.

24. Maroo J., V. T. Vasu S. Gupta Dose dependent hypoglycemic effect of aqueous extract of $E$. littorale Blume in alloxan induced diabetic rats, Phytomedicine, 2003; 10: 196199.

25. Vishwakarma Santosh L. Bagul Milind S. Rajani M. Goyal Ramesh K. A sensitive HPTLC method for estimation of swertiamarin in $E$. littorale blume, Journal of planar chromatography, 2004; 17: 128131.

26. Upadhyaya UM, Goyak RK. Efficacy of $E$. littorale in type 2 diabetic patients. Phyto Res 2004; 18: 233-235

27. Prince PSM, Srinivasan M. Enicostemma littorale Blume aqueous extract improves the antioxidant status in alloxan induced diabetic rat tissues. Acta Pol Pharm Drug Res 2005; 62(5): 363-367.

28. Jaishree Vaijanathappa, Shrisshailappa Badami and Suresh Bhojraj, Invitro anti-oxidant activity of Enicostemma axillare, Journal of Health Science, 2008; 54: 524-528.

29. Gite VN, Pokharkar RD, Chopade VV, Takate SB. Hepatoprotective activity of Enicostemma axillare in paracetamol induced hepatotoxicity 
in albino rats. Int $\mathrm{J}$ Phar life Sci 2010; 1(2): 50-53.

30. Sarita Gupta, Nidheesh Dadheech, Anubha Singh, Sanket Soni and R R Bhonde, Enicostemma littorale: A new therapeutic target for islet neogenesis, International Journal of Integrative Biology, 2010; 10: 4953.

31. Shukla Amarnath, Shukla HM. Single blind placebo contolled clinical evaluation of mamajjaka ghanvati in prameha with special reference to diabetes mellitus. Journal of Ayurveda and Holistic Medicine, 2013; 1(5): 11-9.

32. Gohil Ta, Patel JK, Vaghasiya JD, Mane ant hyperglycemic and antihyperinsulinemic effect of aqueous extract of Aegle marmelos leaf and Enicostemma littorale, Ind J Pharm, 2008; 40(2): 66-91.

33. Gopal R, A. Gnanamani, Udayakumar and S. Sadulla. Enicostemma littorale Blume a potential hypolipidaemic plant, Natural Product Radiance, 2004; 3: 401-405.

34. Vihas T. Vasu, Hiren Modi, Jyoti v. Thaikoottathil and Sarita Gupta, Hypolipidaemic and antioxidant effect of Enicostemma littorale Blume. Aqueous extract in cholesterol fed rats, Journal of Ethnopharmacology, 2005; 101: 277-282.

35. Hitesh Vaidya, Mandapati Rajani, Vasudevan Sudarsanam, Harish Padh, Ramesh Goyal, Swertiamarin: A lead from Enicostemma littorale Blume for antihyperlipidaemic effect, 2009; 617:108-112.

36. Gupta R.S., and Dharmendra Singh, Hepatomodulatory role of Enicostemma littorale Blume against oxidative stress induced liver injury in rats, African Journal of Agricultural Research, 2007; 2: 131-138.

37. Natarajan PN, Prasad S: Chemical investigation of E. littorale. Planta Med, 2002, 22: 42-46.

38. Ghosal S, Jaiswal DK: Chemical constitution of Gentianaceae 28: Flavonoids of E. hyssopifolim (Wild) Verd. J Pharm Sci 1: 53-56.

39. Bhatt NM, Barua S, Gupta S. Protective effect of Enicostemma littorale Blume on rat model of diabetic neuropathy. Am J Infect Dis 2009; 5(2): 106-112.

\section{Cite article:}

Understanding the pharmacokinetics of mamajjaka (enicostemma littorale blume) as a dietary supplement in diabetes mellitus.

D. V. Kulkarni, Pranita Mali, D. B. More

Ayurlog: National Journal of Research in Ayurved Science-2018 6(3): 1-10 